\title{
Theoretical Prediction of Thermophysical Properties of Waste Beef Tallow Biodiesel
}

\author{
Gokul Raghavendra Srinivasan \\ Research Scholar \\ $\mathrm{CO}_{2}$ Research and Green Technologies Centre \\ Vellore Institute of Technology, \\ Vellore-632014, India \\ gokusrinivasan@gmail.com
}

\author{
Ranjitha Jambulingam \\ Assistant Professor \\ $\mathrm{CO}_{2}$ Research and Green Technologies Centre \\ Vellore Institute of Technology, \\ Vellore-632014, India \\ ranjitha.j@vit.ac.in
}

\begin{abstract}
Biodiesel are the most promising alternates for the existing fossil fuel because of their robust energy output with enhanced performance, combustion characteristics with reduced emissions level. The necessity of evaluating their physical, chemical and thermal properties helps in better understanding their behavior during their applications. This paper deals with the prediction of thermophysical properties of beef tallow biodiesel, theoretically, using fatty acid esters by means of mathematical modeling. The waste beef tallow was rendered from animal slaughter houses and tanneries' leather fleshing wastes; and was transesterified into biodiesel using base catalyzed ethanolysis. Ethyl Palmitate (C16:0), Ethyl Oleate (C18:1) and Ethyl Stearate (C18:0) were identified as the dominant fatty acid esters and their corresponding distribution were determined to be $37.36 \%, 25.17 \%$ and $14.78 \%$ respectively. Physical properties like density, Kinematic Viscosity were determined based on the molecular weight of individual fatty acid esters whereas chemical properties like saponification value and iodine value were based on the degree of unsaturation and number of individual atoms present in those ester molecules. Thermal properties like Cetane Number and Higher Heating Value were based on the determined chemical properties and molecular structure of individual fatty acid esters. The thermophysical properties were computed considering both mass fraction and mole fraction of fatty acid ester molecule individually. The computed values were compared with the experimental data determined according to ASTM standard methods and; Absolute Deviation and Absolute Percentage Error were found between these values to ensure the accuracy of developed empirical correlations.
\end{abstract}

Keywords - Beef Tallow Biodiesel, Fatty Acid Ethyl Esters, Mathematical Modeling, Molecular Weight, unsaturated double bonds

\section{INTRODUCTION}

The demand for biodiesel is being widely growing in both developed and developing countries to meet their increasing energy demand in a sustainable way. Biodiesel is common name for any fatty acid alkyl ester produced by transesterifying fatty acids in triglyceride molecule present in animal fat or vegetable oil, with short chained alcohol in presence of catalyst under optimized condition. It widely known for its fair advantages like non toxicity, higher biodegradability, higher engine performance with reduced engine parts wear and reduced emissions; thereby making it as a self-sustaining and environmental friendly biofuel. [1]. Biodiesel is superior than petro diesel in terms of reduced $\mathrm{CO}$ and $\mathrm{NO}_{\mathrm{x}}$ Emission, higher sustainability and lower impact on environment.

In general, the quality of biodiesel is decided by its thermo-physical properties which are in turn reflected in its performance, combustion and emission (PCE) characteristics during engine application [2]. Density ( $\rho)$, Kinematic Viscosity (v), Cetane Number (CN) and Higher Heating Value (HHV) are the important thermo-physical properties which signify the quality of biodiesel and have very good influence during its combustion [3].

In general, the atomization of biodiesel during combustion process is deeply influenced by its density and viscosity whereas Cetane Number describes the fuel's ignition delay. Higher Heating Value denotes the quantity of heat released upon combusting unit mass of fuel and bringing back the combustion by-products to its original pre-combustion temperature accounting latent heat of vaporization of water; and is primarily used for defining the probable energy content of the fuel and also its efficiency.

These essential properties must be determined using standard testing methods however these methods are time consuming and must be carried out in sophisticated ambience with higher level of accuracy. This makes the determination of thermo physical properties exhaustive and takes much longer time for proceeding with further analyses. In addition, large quantity of fuel sample is required for these analytic works which makes it challenging for fuel samples available in lesser quantity. To minimize these constraints, a novel approach of developing mathematical correlations to predict these vital properties were attempted and was accomplished by correlating their extensive molecular properties. It was clearly evident that the characteristics of any biodiesel were deeply influenced by the characteristics of individual fatty acid esters [4].

In relevance to that, numerous mathematical equations have been developed to either predict or correlate these properties by relating the properties of individual fatty acid ester molecule. Accordingly, the Smittenberg 
Relation was applied on saturated methyl esters to predict their density at two different temperatures $\left(20^{\circ} \mathrm{C}\right.$ and $40^{\circ} \mathrm{C}$ respectively) [5]. Also, empirical correlations were developed to predict the viscosity of the biodiesel by correlating various molecular functions and their corresponding polynomial degree. In connection with that molecular weight was considered for determining viscosity using quadratic equation [6] whereas Krisnangkura et al., 2006 correlated viscosity with number of carbon atoms and temperature [7]. In addition, another physical property called Surface tension, which describes about the ability of the fluid to resist force on the surface, was successfully predicted for all type of FAE's using Sugden's Parachor method, a modified version of Macleod's Equation [8,9]. Klopfenstein., 1985 proposed a non-linear equation for fatty acid ester which correlated the length of carbon chain with Cetane Number [10] and was found to be in contrast in case of normal hydrocarbon chains.

In this present study, simple linear equations were developed for predicting the thermo-physical properties by considering molecular weight and number of double bonds as two independent variables. Interestingly, molecular weight signifies as a function of carbon chain length and number of carbon molecules in it whereas numbers of double bond signifies the degree of unsaturation.

\section{MATERIALS AND METHODOLOGY}

\section{A. Sample Collection}

The waste beef tallow was rendered from fleshing and subcutaneous wastes from leather tanneries and animal slaughter houses respectively. The wastes were autoclaved @ $120^{\circ} \mathrm{C}, 15$ bar pressure to separate tallow from non-lipid organic wastes. The rendered tallow was water washed, dehydrated and degummed using Orthophosphoric Acid [11]. The refined fat was preserved under refrigeration to avoid any contamination and prevent rancdification (oxidation of tallow).

\section{B. Preparation of Beef Tallow Biodiesel}

The refined tallow was subjected for base catalyzed transesterification using ethanol as solvent. The reaction parameters carried out are as follows: Influencing parameters [1:6 oil to ethanol ; $0.5 \%$ catalyst concentration of Potassium Hydroxide], Operating parameters [ $60^{\circ} \mathrm{C}, 350 \mathrm{RPM}, 60$ minutes] [12].The reaction mixture was separated under the influence of gravity and biodiesel was water washed repeatedly to remove any impurities.

\section{Quantification of Fatty Acid Esters}

The Fatty Acid Ethyl Esters (FAEs) were quantified using Gas Chromatography and Mass Spectrometry. The FAEs were identified by the peak obtained at their corresponding retention time and the quantities of FAEs were represented by the area of peak occupied. The quantified Fatty Acid Esters were considered for the purpose of developing empirical correlations for the thermo-physical properties. The standard values of thermo physical properties of identified FAEs were referenced from the library (standard library) and earlier literatures. The thermophysical properties of Ethyl Tallowate were determined using ASTM standard.

\section{Mathematical Modelling of Empirical Correlations}

The Theoretical evaluation of thermo-physical properties of beef tallow biodiesel was carried out by developing empirical correlations based on the data series from properties of individual fatty acid esters using design expert software. Equations 1-4 signifies the developed correlation for Density, Kinematic Viscosity, Cetane Number and Higher Heating Value respectively; and were fitted linearly by means of statistical regression of varying physical properties for different molecular weight and degree of unsaturation. Here $M W_{E}$ denotes the molecular weight of the corresponding fatty acid ester molecule whereas $N_{E}$ signifies the number of double bond present in fatty acid chain of the ester molecule.

$$
\begin{aligned}
& \text { Density }=881.86-\left(0.07 * M W_{\mathrm{E}}\right)+\left(11.91 * N_{\mathrm{E}}\right) \\
& \text { Kinematic Viscosity }=-5.59+\left(0.04 * M W_{\mathrm{E}}\right)-\left(0.78 * N_{\mathrm{E}}\right) \\
& \text { Cetane Number }=10.25+\left(0.25 * M W_{\mathrm{E}}\right)-\left(21.09 * N_{\mathrm{E}}\right) \\
& \text { Higher Heating Value }=25.7+\left(0.057 * M W_{\mathrm{E}}\right)-\left(3.16 * N_{\mathrm{E}}\right)
\end{aligned}
$$

In general, thermo-physical properties of any biodiesel can be evaluated theoretically by considering mole or mass fraction along with properties of individual fatty acid esters. Equation 5 represents the generalized expression for determining the properties based on mass fraction whereas Equation 6 represents the generalized expression for determining the properties based on mole fraction. 


$$
\begin{gathered}
Y=\sum_{i=1}^{n} m_{i} . f_{i} \\
Y=\sum_{i=1}^{n} x_{i} \cdot f_{i}
\end{gathered}
$$

Where $Y$ is any thermophysical property of the sample, $f i$ is the thermophysical property of the individual fatty acid ester, $m_{i}$ is mass fraction for the corresponding FAE, $x_{i}$ is the mole fraction of corresponding FAE determined using equation 7 by substituting the molecular weight of individual fatty acid ester along with its corresponding mass fraction.

$$
x_{i}=\frac{\frac{m_{i}}{M W_{E}}}{\sum_{i=1}^{n}\left(\frac{m_{i}}{M W_{E}}\right)}
$$

Similarly, the average absolute percentage error (AAPE) between the calculated and experimental values was determined using equation 8 :

$$
A A P E=\left(\frac{1}{n}\right) \sum_{i=1}^{n}\left|\left(\frac{\left(f_{i} \exp -f_{i} c a l\right)}{f_{i} c a l} * 100\right)\right|
$$

Where, $\mathrm{n}$ is the number of fatty acid esters considered for the study, $f_{i}^{\text {exp }} \& f_{i}^{\text {cal }}$ are the experimental and calculated thermo-physical properties.

\section{RESULTS AND DISCUSSIONS}

\section{A. Characterization and quantification of Beef Tallow Biodiesel}

Biodiesel produced from waste beef tallow rendered from leather fleshing and animal slaughter house wastes were characterized for various fatty acid esters molecules using GC spectra and were identified along with \% availability based on retention time of the peak and area occupied by the peak respectively. Figure 1 illustrates the GC spectra of waste beef tallow biodiesel. It was concluded that Ethyl Oleate, Ethyl Palmitate and Ethyl Stearate were identified as dominant fatty acid esters and have an influencing role in the properties of biodiesel. Table 1 summarizes the characterized FAE along with their retention time, availability and molar fraction.

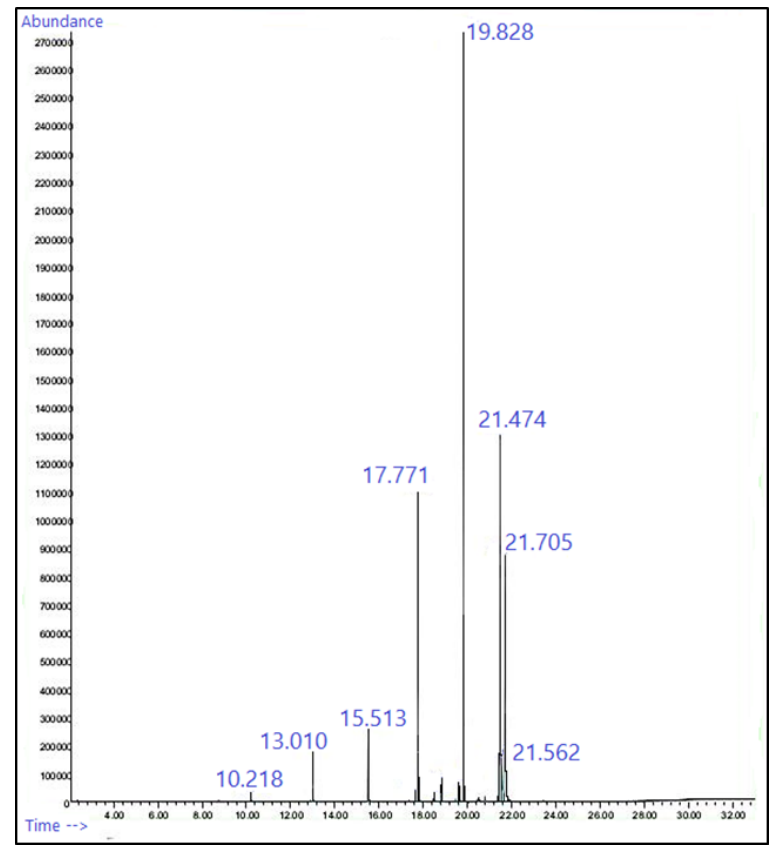

Figure1: GC Spectra of Waste Tallow Biodiesel 


\section{B. Properties of Fatty Acid Esters:}

Upon characterizing the biodiesel, the thermo physical properties like density, Kinematic Viscosity, Cetane Number and Higher Heating Value of individual fatty acid ethyl ester were reported from existing literatures and standard databases and are tabulated in table 2. The theoretical values for individual fatty acid esters were computed using the mathematical correlations (Equation 1 to 4) developed using statistical regression. The Average Absolute Deviation (AAD) and Average Absolute Percentage Error (AAPE) between experimental and predicted values were found to be 0.269 \& $0.062 \%$ for Density; 0.041 \& $2.611 \%$ for Kinematic Viscosity; 1.35 \& $4.01 \%$ for Cetane Number; and 0.453 \& $2.222 \%$ for Higher Heating Value respectively. Table 3 summarizes the absolute deviation and absolute percentage error between the reported and calculated values for individual fatty acid esters.

On assessing the thermophysical properties of individual fatty acid esters, it was found that Kinematic Viscosity, Cetane Number and Higher Heating Value increased with increase in molecular weight whereas density decreased with increase in molecular weight. However, Kinematic Viscosity, Cetane Number and Higher Heating Value decreased with increasing number of double bond but increased in case of density.

Density:

From equation 1, it was clearly evident that density decreased with increase in molecular weight whereas increased with increase in degree of unsaturation. The inverse proportionality between density and molecular weight is signified by the negativity of latter function and the degree of unsaturation with positive sign signifies direct proportionality. In general, the densities of fatty acids are inversely proportional to their corresponding number of carbon atoms which decreases marginally at higher number of carbon atom [5].Accordingly, the density of fatty acid esters also decreased significantly for esters with smaller number of carbon atoms ( $\mathrm{C} 8$ to $\mathrm{C} 12$ ) followed by marginal decrease in density for fatty acid esters with larger number of carbon atoms. From figure 2, the experimental values were found to be well fit with the predicted model within the $95 \%$ confidence band and can be concluded that density decreased by $1.332 \mathrm{Kg} / \mathrm{m}^{3}$ on average for saturated fatty acid esters whereas decreased by $1.45 \mathrm{Kg} / \mathrm{m}^{3}$ on average for unsaturated fatty acid esters. Similarly, the density of unsaturated C14:1, C16:1 \& C18:1 ethyl ester was found to be $1.41 \%, 1.5 \%$ \& $1.6 \%$ higher than the saturated C14:0, C16:0 \& C18:0 ethyl esters respectively. Eventually, the Average Absolute Deviation (AAD) and average Absolute Percentage Error (AAPE) between the reported and predicted values were found to be 0.246 and $0.057 \%$ respectively.



Figure 2 : Density of Fatty Acid Esters as function of Molecular Weight

Kinematic Viscosity:

From equation 2, it was clearly evident that Kinematic Viscosity increased with increase in molecular weight whereas decreased with increase in degree of unsaturation. Kinematic Viscosity of fatty acid ester was found to be directly proportional to its molecular weight and inversely proportional to its degree of unsaturation. The direct proportionality between Kinematic Viscosity and molecular weight is signified by the positivity of latter function whereas the degree of unsaturation with negative sign signifies inverse 
proportionality. Based on the reported Kinematic Viscosity of fatty acid esters, it is evident that viscosity increases progressively along carbon chain length owing to the increasing Van der Waals forces along the nonpolar length of the ester molecule. This Van der Waals intermolecular attraction is a resultant of zig-zag arrangement of carbon atoms with tetrahedral bond angles along the linear fatty acid chain and occurs between SP3 hybridization atoms. From figure 3, the experimental values were found to be well fit with the predicted model within the $95 \%$ confidence band and can be concluded that Kinematic viscosity increased by $0.685 \mathrm{~mm}^{2} / \mathrm{S}$ on average for saturated fatty acid esters whereas Kinematic viscosity increased by $1.02 \mathrm{~mm}^{2} / \mathrm{S}$ on average for unsaturated fatty acid esters. In contrast, the viscosity of unsaturated C14:1, C16:1 \& C18:1 ethyl ester was found to be $18.27 \%, 16.3 \%$ \& $18.16 \%$ lesser than the saturated C14:0, C16:0 \& C18:0 ethyl esters respectively. This reduction in viscosity for these unsaturated ester molecules is because of weak Van der Waals intermolecular attraction caused by their CIS-Configuration, which hold back the approaching SP2 atoms (from double bond) from neighboring molecules. Ultimately, the Average Absolute Deviation (AAD) and average Absolute Percentage Error (AAPE) between the reported and predicted values were found to be 0.092 and $6.58 \%$ respectively.

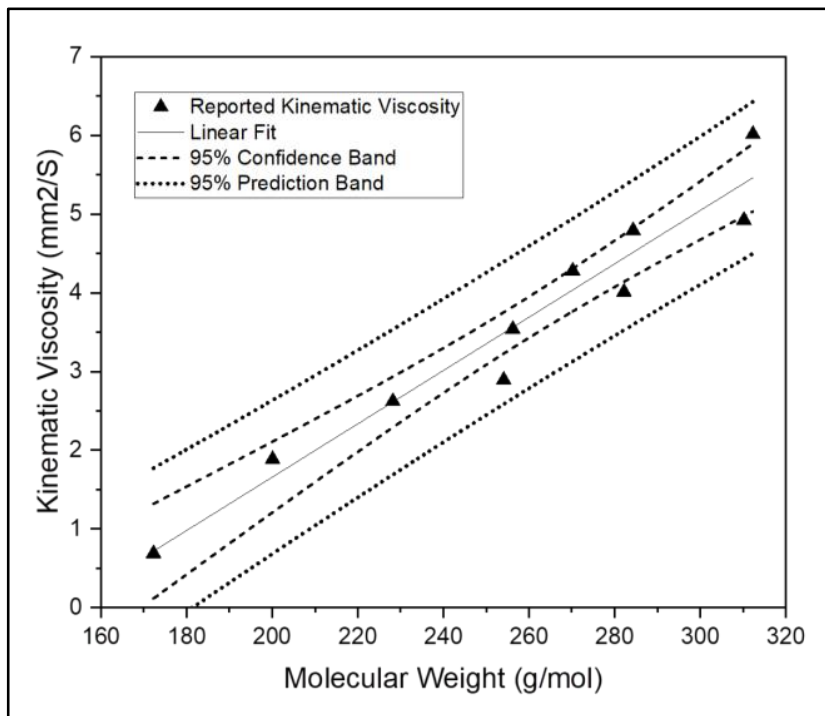

Figure 3 : Kinematic Viscosity of Fatty Acid Esters as function of Molecular Weight

Cetane Number:

From equation 3, it was clearly evident that Cetane Number increased with increase in molecular weight whereas decreased with increase in degree of unsaturation. Cetane Number of fatty acid ester was found to be directly proportional to its molecular weight and inversely proportional to its degree of unsaturation. The direct proportionality between Cetane and molecular weight is signified by the positivity of latter function whereas the degree of unsaturation with negative sign signifies inverse proportionality. Cetane Number serves as an indicator for combustion speed of fuel \& ignition delay; and increases for fatty acid esters as their molecular weight increases. From figure 4, the experimental values were found to be well fit with the predicted model within the $95 \%$ confidence band and can be concluded that cetane number increased by 5.08 units on average for saturated fatty acid esters whereas cetane number increased by 6.96 units on average for unsaturated fatty acid esters. However, the cetane number of unsaturated C14:1, C16:1 \& C18:1 ethyl ester were found to be $27.07 \%, 33.68 \%$ \& $25.64 \%$ lesser than the saturated C14:0, C16:0 \& C18:0 ethyl esters respectively. This reduction in Cetane Number for unsaturated esters is a result of unsaturated double bonds moving towards the center of the fatty acid ester chain. Further, the Average Absolute Deviation (AAD) and average Absolute Percentage Error (AAPE) between the reported and predicted values were found to be 0.66 and $1.88 \%$ respectively. 


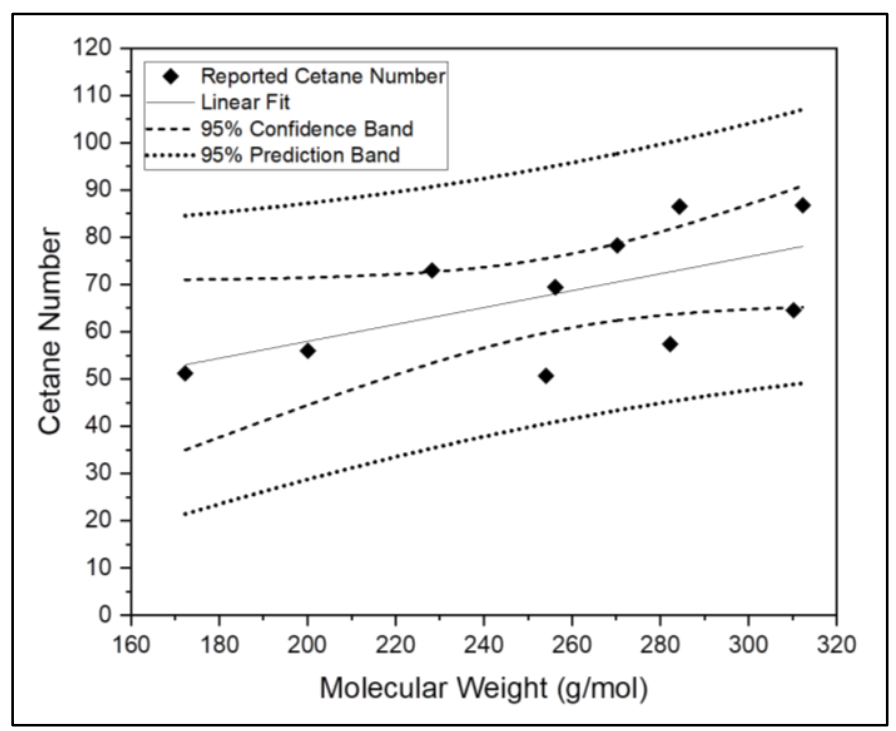

Figure 4: Cetane Number of Fatty Acid Esters as function of Molecular Weight

\section{Higher Heating Value:}

From equation 2, it was clearly evident that Higher Heating Value increased with increase in molecular weight whereas decreased with increase in degree of unsaturation. The Higher Heating Value of fatty acid ester was found to be directly proportional to its molecular weight and inversely proportional to its degree of unsaturation. The direct proportionality between Higher Heating Value and molecular weight is signified by the positivity of latter function whereas the degree of unsaturation with negative sign signifies inverse proportionality. Based on the reported Higher Heating Value of fatty acid esters, it is evident that the heating value increases progressively along carbon chain length owing to the increasing number of $\mathrm{C}-\mathrm{H}$ bonds, which has higher bond enthalpy. from figure 5 , the experimental values were found to be well fit with the predicted model within the $95 \%$ confidence band and can be concluded that Higher Heating value increased by 0.83 $\mathrm{MJ} / \mathrm{Kg}$ on average for saturated fatty acid esters whereas Higher Heating value increased by $1.9 \mathrm{MJ} / \mathrm{Kg}$ on average for unsaturated fatty acid esters. In contrast, the Higher Heating Value of unsaturated C14:1, C16:1 \& $\mathrm{C} 18: 1$ ethyl ester was found to be $7 \%, 3.28 \%$ \& $5.21 \%$ lesser than the saturated $\mathrm{C} 14: 0, \mathrm{C} 16: 0$ \& $\mathrm{C} 18: 0$ ethyl esters respectively. This reduction in Higher Heating Value for these unsaturated ester molecules is because of lesser availability of hydrogen atoms (for $\mathrm{C}-\mathrm{H}$ bond) which lowers the heating value Inspite of availability of $\mathrm{C}=\mathrm{C}$ bond present in fatty acid carbon chain. Taken together, the Average Absolute Deviation (AAD) and average Absolute Percentage Error (AAPE) between the reported and predicted values were found to be 0.082 and $0.43 \%$ respectively.

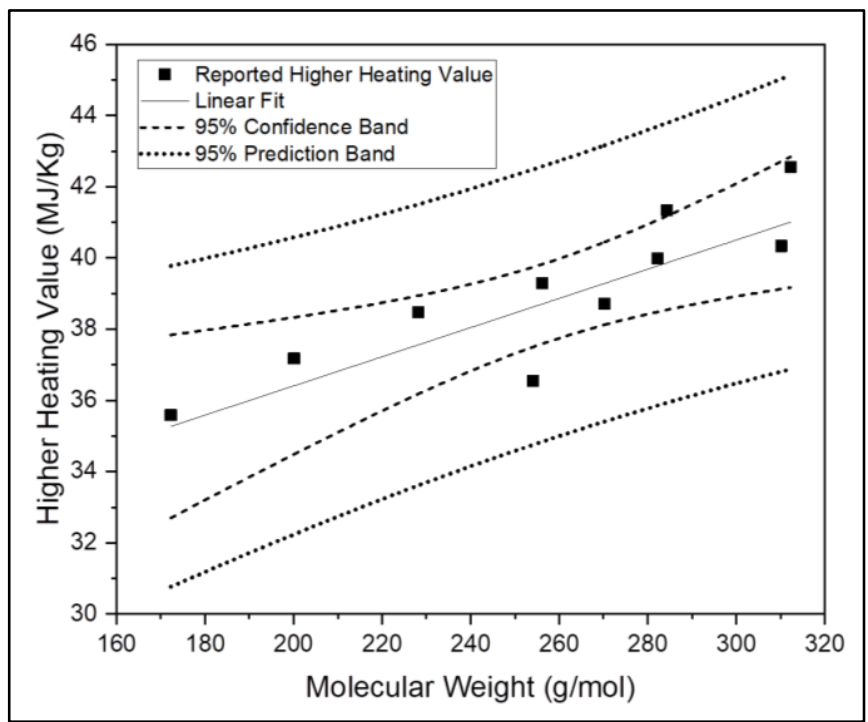

Figure 5 : Higher Heating Value of Fatty Acid Esters as function of Molecular Weight 


\section{Properties of Beef Tallow Biodiesel:}

Density:

Density describes the amount of fuel that can be occupied with its unit volume and is altered as temperature and pressure varies proportionally. In addition, density governs the fuel injection in $\mathrm{Cl}$ engine where large amount of fuel will be injected for same volume in case of denser fuel when compared to less denser fuel. The density of biodiesel produced from waste beef tallow was determined by measuring the mass against a known volume and was measured as $883 \mathrm{~kg} / \mathrm{m}^{3}$. The Absolute Deviation (AD) for density between experimental value and mole fraction \& mass fraction value was found to be 8.24 and 8.28 respectively whereas Absolute Percentage Error (APE) for density between experimental value and mole fraction \& mass faction value was found to be $1.9 \%$ and $1.91 \%$. Table 4 summarizes the Absolute Deviation and Absolute Percentage Error for density between experimental value and mole fraction \& mass faction method value.

Kinematic Viscosity:

Kinematic Viscosity describes about the internal resistance to fluid's flow when gravity acts on it; and increases for biodiesel with high carbon chained fatty acid esters. Spray characteristics of fuel like droplet size \& penetration, effectiveness of atomization are deeply influenced by the Kinematic Viscosity and tends to produce larger droplets accompanied with poor atomization for high viscosity biodiesel, resulting in reduced combustion \& increased cylinder deposits. Apart from spray characteristics, higher viscosity fuel requires more pump work which causes increased wear rate for fuel injection components thereby reducing the engine performance rate. The Kinematic Viscosity of biodiesel produced from waste beef tallow was determined according to ASTM D 445-04e specification and was calculated as $4.6 \mathrm{~mm}^{2} / \mathrm{s}$, which was found to be well inside the permissible range $\left(1.9-6 \mathrm{~mm}^{2} / \mathrm{s}\right)$. The Absolute Deviation (AD) for Kinematic Viscosity between experimental value and mole fraction \& mass faction value was found to be 0.058 and 0.021 respectively whereas Absolute Percentage Error (APE) for Kinematic Viscosity between experimental value and mole fraction \& mass faction value was found to be $2.49 \%$ and $0.91 \%$. Table 5 summarizes the Absolute Deviation and Absolute Percentage Error for Kinematic Viscosity between experimental value and mole fraction \& mass faction method value.

\section{Cetane Number:}

Cetane Number serves as an indicator for combustion speed of fuel \& ignition delay; and increases for biodiesel with high saturated fatty acid esters. Biodiesel with higher Cetane Number provide complete combustion accompanied by smooth running of engine whereas lower Cetane Number results in increased exhaust emission owing to incomplete combustion. In addition, higher Cetane Number improves the cold-start behavior and reduces knocking \& white smoke. The Cetane Number of biodiesel produced from waste beef tallow was determined according to ASTM D 613-05 standard and was measured as 72, which was 53.19\% greater than the minimum required limit. The Absolute Deviation (AD) for Cetane Number between experimental value and mole fraction \& mass faction value was found to be 1.94 and 1.84 respectively whereas Absolute Percentage Error (APE) for Cetane Number between experimental value and mole fraction \& mass faction value was found to be $5.12 \%$ and $4.87 \%$. Table 6 summarizes the Absolute Deviation and Absolute Percentage Error for Cetane Number between experimental value and mole fraction \& mass faction method value. 
Table 1 summarizes the characterized Fatty Acid Esters along with their retention time, availability and molar fraction

\begin{tabular}{|c|c|c|c|c|c|c|c|}
\hline $\begin{array}{l}\text { S. } \\
\text { No }\end{array}$ & $\begin{array}{l}\text { Carbon } \\
\text { Number }\end{array}$ & Fatty Acid Ester Name & $\begin{array}{l}\text { Molecular } \\
\text { Formula }\end{array}$ & $\begin{array}{c}\text { Molecular } \\
\text { Weight, } \\
\text { g/mol }\end{array}$ & $\begin{array}{c}\text { Availability, } \\
\%\end{array}$ & $\begin{array}{c}\text { Number } \\
\text { of } \\
\text { double } \\
\text { bonds }\end{array}$ & $\begin{array}{c}\text { Mole } \\
\text { Fraction, } \\
\mathrm{x}_{\mathrm{i}} \text { Value }\end{array}$ \\
\hline 2 & C10:0 & Decanoic Acid Ethyl Ester & $\mathrm{C}_{12} \mathrm{H}_{24} \mathrm{O}_{2}$ & 200.1 & 2.3 & 0 & 0.016064 \\
\hline 3 & C12:0 & Dodecanoic Acid Ethyl Ester & $\mathrm{C}_{14} \mathrm{H}_{28} \mathrm{O}_{2}$ & 228.2 & 3.13 & 0 & 0.024931 \\
\hline 6 & C14:2 & Undecanoic Acid,2,8-Dimethyl-,Methyl Ester & $\mathrm{C}_{14} \mathrm{H}_{28} \mathrm{O}_{2}$ & 270.2 & 0.45 & 0 & 0.004244 \\
\hline 7 & C15:0 & Pentadecanoic Acid Ethyl Ester & $\mathrm{C}_{17} \mathrm{H}_{34} \mathrm{O}_{2}$ & 270.2 & 0.86 & 0 & 0.008111 \\
\hline 8 & C16:1 & E-11-Hexadecenoic Acid Ethyl Ester & $\mathrm{C}_{18} \mathrm{H}_{34} \mathrm{O}_{2}$ & 282.2 & 1.16 & 1 & 0.011426 \\
\hline 9 & C16:0 & Hexadecanoic Acid Ethyl Ester & $\mathrm{C}_{18} \mathrm{H}_{36} \mathrm{O}_{2}$ & 284.3 & 37.36 & 0 & 0.370728 \\
\hline 10 & C18:1 & Oleic Acid Ethyl Ester & $\mathrm{C}_{20} \mathrm{H}_{38} \mathrm{O}_{2}$ & 310.2 & 25.17 & 1 & 0.272519 \\
\hline
\end{tabular}

Table 2 consolidates the reported and calculated thermo-physical properties of Fatty Acid esters

\begin{tabular}{|c|c|c|c|c|c|c|c|c|}
\hline $\begin{array}{l}\text { Carbon } \\
\text { Number }\end{array}$ & $\begin{array}{l}\text { Density } \\
\left(\mathrm{Kg} / \mathrm{m}^{3}\right) \\
(\text { Reported } \\
\left.@ 15^{\circ} \mathrm{C}\right)\end{array}$ & $\begin{array}{c}\text { Density } \\
\left(\mathrm{Kg} / \mathrm{m}^{3}\right) \\
\text { (Calculated } \\
\left.@ 15^{\circ} \mathrm{C}\right)\end{array}$ & $\begin{array}{c}\text { Kinematic } \\
\text { Viscosity } \\
\left(\mathrm{mm}^{2} / \mathrm{s}\right) \\
\text { (Reported } \\
\left.@ 40^{\circ} \mathrm{C}\right)\end{array}$ & $\begin{array}{c}\text { Kinematic } \\
\text { Viscosity } \\
\left(\mathrm{mm}^{2} / \mathrm{s}\right) \\
\text { (Calculated } \\
\left.@ 40^{\circ} \mathrm{C}\right)\end{array}$ & $\begin{array}{c}\text { Cetane } \\
\text { Number } \\
\text { (Reported) }\end{array}$ & $\begin{array}{c}\text { Cetane } \\
\text { Number } \\
\text { (Calculated) }\end{array}$ & $\begin{array}{l}\text { Higher } \\
\text { Heating } \\
\text { Value } \\
\text { (MJ/Kg) } \\
\text { (reported) }\end{array}$ & $\begin{array}{c}\text { Higher } \\
\text { Heating } \\
\text { Value } \\
\text { (MJ/Kg) } \\
\text { (Calculated) }\end{array}$ \\
\hline & [13] & & [13] & & [13] & & [13] & \\
\hline C8:0 & 871.6 & 870.67 & 0.69 & 0.69 & 51.23 & 53.01 & 35.58 & 35.58 \\
\hline C10:0 & 868.4 & 868.86 & 1.89 & 1.70 & 56 & 59.91 & 37.18 & 37.18 \\
\hline C12:0 & 866.4 & 867.03 & 2.62 & 2.73 & 73 & 66.89 & 38.47 & 38.79 \\
\hline C14:1 & 877 & 877.26 & 2.89 & 2.89 & 50.65 & 52.22 & 36.55 & 37.12 \\
\hline C14:0 & 864.8 & 865.21 & 3.54 & 3.75 & 69.45 & 73.83 & 39.29 & 40.40 \\
\hline C14:2 & 864 & 864.31 & 4.28 & 4.26 & 78.29 & 77.31 & 38.71 & 41.20 \\
\hline C15:0 & 864 & 864.31 & 4.28 & 4.26 & 78.29 & 77.31 & 38.71 & 41.20 \\
\hline C16:1 & 876.3 & 875.44 & 4.01 & 3.91 & 57.40 & 59.19 & 39.99 & 38.73 \\
\hline C16:0 & 863.4 & 863.39 & 4.79 & 4.77 & 86.55 & 80.81 & 41.34 & 42.01 \\
\hline C18:1 & 874.1 & 873.62 & 4.92 & 4.93 & 64.57 & 66.14 & 40.34 & 40.34 \\
\hline C18:0 & 860.33 & 861.57 & 6.02 & 5.79 & 86.83 & 87.76 & 42.55 & 43.61 \\
\hline
\end{tabular}

Table 3 consolidates the Absolute deviation and Absolute percentage error for various Fatty Acid esters

\begin{tabular}{|c|c|c|c|c|c|c|c|c|}
\hline \multirow{2}{*}{$\begin{array}{c}\text { Carbon } \\
\text { Number }\end{array}$} & \multicolumn{2}{|c|}{ Density } & \multicolumn{2}{|c|}{ Kinematic Viscosity } & \multicolumn{2}{|c|}{ Cetane Number } & \multicolumn{2}{|c|}{ Higher Heating Value } \\
\hline & $A D$ & $\mathrm{APE}, \%$ & $A D$ & $\mathrm{APE}, \%$ & $A D$ & $\mathrm{APE}, \%$ & $A D$ & APE, $\%$ \\
\hline $\mathrm{c} 8: 0$ & 0.467 & 0.107 & 0.001 & 0.373 & 0.890 & 3.359 & 0 & 0 \\
\hline c10:0 & 0.230 & 0.053 & 0.091 & 10.713 & 1.956 & 6.529 & 0 & 0 \\
\hline $\mathrm{c} 12: 0$ & 0.317 & 0.073 & 0.053 & 3.914 & 3.057 & 9.141 & 0.162 & 0.833 \\
\hline $\mathrm{c} 14: 1$ & 0.131 & 0.030 & 0.002 & 0.139 & 0.786 & 3.010 & 0.285 & 1.54 \\
\hline c14:0 & 0.207 & 0.048 & 0.105 & 5.605 & 2.192 & 5.939 & 0.552 & 2.731 \\
\hline c14:2 & 0.153 & 0.035 & 0.010 & 0.477 & 0.489 & 1.265 & 1.243 & 6.035 \\
\hline $\mathrm{c} 15: 0$ & 0.153 & 0.035 & 0.010 & 0.477 & 0.489 & 1.265 & 1.243 & 6.035 \\
\hline c16:1 & 0.432 & 0.099 & 0.050 & 2.558 & 0.899 & 3.036 & 0.628 & 3.244 \\
\hline C16:0 & 0.005 & 0.001 & 0.010 & 0.432 & 2.871 & 7.105 & 0.333 & 1.586 \\
\hline c18:1 & 0.242 & 0.055 & 0.004 & 0.174 & 0.786 & 2.376 & 0 & 0 \\
\hline c18:0 & 0.620 & 0.144 & 0.112 & 3.853 & 0.464 & 1.057 & 0.531 & 2.434 \\
\hline Average & 0.269 & 0.062 & 0.041 & 2.611 & 1.353 & 4.008 & 0.453 & 2.222 \\
\hline \multicolumn{9}{|c|}{ *Absolute Deviation ${ }^{* *}$ Absolute Percentage Error } \\
\hline
\end{tabular}


Table 4: Absolute deviation and Absolute percentage error of Density between experimental value and mole fraction \& mass faction method value

\begin{tabular}{|c|c|c|c|}
\hline \multirow{3}{*}{ Source } & \multicolumn{3}{|c|}{ Density, $\mathrm{Kg} / \mathrm{m}^{3}$} \\
\hline & $\begin{array}{l}\text { Experimental } \\
\text { Value }\end{array}$ & $\begin{array}{c}\text { Mole Fraction Method } \\
\rho_{\text {biodiesel }}=\sum_{\mathrm{i}=1}^{\mathrm{n}} \mathrm{x}_{\mathrm{i}} * \rho_{\mathrm{i}}\end{array}$ & $\begin{array}{c}\text { Mass Fraction Method } \\
\rho_{\text {biodiesel }}=\sum_{\mathrm{i}=1}^{\mathrm{n}} \mathrm{m}_{\mathrm{i}} * \rho_{\mathrm{i}}\end{array}$ \\
\hline & (Experimental) & (Calculated) & (Calculated) \\
\hline Beef Tallow Ethyl ester & 883 & 866.52 & 866.45 \\
\hline Absolute Deviation & - & 8.24 & 8.28 \\
\hline $\begin{array}{c}\text { Absolute Percentage } \\
\text { Error }\end{array}$ & - & 1.90 & 1.91 \\
\hline
\end{tabular}

Table 5: Absolute deviation and Absolute percentage error of Kinematic Viscosity between experimental value and mole fraction $\&$ mass faction method value

\begin{tabular}{|c|c|c|c|}
\hline \multirow[b]{2}{*}{ Source } & \multicolumn{3}{|c|}{ Kinematic Viscosity, $\mathrm{mm}^{2} / \mathrm{S}$} \\
\hline & Reported Value & $\begin{array}{c}\text { Mole Fraction Method } \\
v_{\text {biodiesel }}=\sum_{\mathrm{i}=1}^{\mathrm{n}} \mathrm{x}_{\mathrm{i}} * v_{\mathrm{i}}\end{array}$ & $\begin{array}{c}\text { Mass Fraction Method } \\
v_{\text {biodiesel }}=\sum_{\mathrm{i}=1}^{\mathrm{n}} \mathrm{m}_{\mathrm{i}} * v_{\mathrm{i}}\end{array}$ \\
\hline & (Experimental) & (Calculated) & (Calculated) \\
\hline Beef Tallow Ethyl ester & 4.6 & 4.72 & 4.64 \\
\hline Absolute Deviation & - & 0.058 & 0.021 \\
\hline $\begin{array}{c}\text { Absolute Percentage } \\
\text { Error }\end{array}$ & - & 2.49 & 0.91 \\
\hline
\end{tabular}

Table 6: Absolute deviation and Absolute percentage error of Cetane Number between experimental value and mole fraction $\&$ mass faction method value

\begin{tabular}{|c|c|c|c|}
\hline \multirow{3}{*}{ Source } & \multicolumn{3}{|c|}{ Cetane Number } \\
\hline & Reported Value & $\begin{array}{l}\text { Mole Fraction Method } \\
\mathrm{CN}_{\text {biodiesel }=\sum_{\mathrm{i}=1}^{\mathrm{n}} \mathrm{x}_{\mathrm{i}} * \mathrm{CN}_{\mathrm{i}}}\end{array}$ & $\begin{array}{l}\text { Mass Fraction Method } \\
\mathrm{CN}_{\text {biodiesel }}=\sum_{\mathrm{i}=1}^{\mathrm{n}} \mathrm{m}_{\mathrm{i}} * \mathrm{CN}_{\mathrm{i}}\end{array}$ \\
\hline & (Experimental) & (Calculated) & (Calculated) \\
\hline Beef Tallow Ethyl ester & 72 & 75.89 & 75.69 \\
\hline Absolute Deviation & - & 1.94 & 1.84 \\
\hline $\begin{array}{c}\text { Absolute Percentage } \\
\text { Error }\end{array}$ & - & 5.12 & 4.87 \\
\hline
\end{tabular}

Table 7: Absolute deviation and Absolute percentage error of Higher Heating Value between experimental value and mole fraction \& mass faction method value

\begin{tabular}{|c|c|c|c|}
\hline \multirow{3}{*}{ Source } & \multicolumn{3}{|c|}{ Higher Heating Value, $\mathrm{MJ} / \mathrm{Kg}$} \\
\hline & Reported Value & 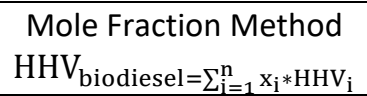 & $\begin{array}{l}\text { Mass Fraction Method } \\
\mathrm{HHV}_{\text {biodiesel }}=\sum_{\mathrm{i}=1}^{\mathrm{m}} \mathrm{m} * \mathrm{HHV}_{\mathrm{i}}\end{array}$ \\
\hline & (Experimental) & (Calculated) & (Calculated) \\
\hline Beef Tallow Ethyl ester & 41 & 41.37 & 41.29 \\
\hline Absolute Deviation & - & 0.18 & 0.14 \\
\hline $\begin{array}{c}\text { Absolute Percentage } \\
\text { Error }\end{array}$ & - & 0.89 & 0.69 \\
\hline
\end{tabular}




\section{Higher Heating Value:}

Higher Heating Value of biodiesel signifies the energy content available in that biofuel. Biodiesel with Higher HHV signifies the ability to produce higher output rate in engine whereas low HHV biofuel burns with lesser output rate accompanied by increased exhaust emissions. The HHV of biodiesel produced from waste beef tallow was determined according to ASTM D-240-02 specifications and was found to be $41 \mathrm{MJ} / \mathrm{Kg}$, which was found to be well inside the permissible range (35 to $43 \mathrm{MJ} / \mathrm{Kg}$ ). The Absolute Deviation (AD) for Higher Heating Value between experimental value and mole fraction \& mass faction value was found to be 0.18 and 0.14 respectively whereas Absolute Percentage Error (APE) for higher heating value between experimental value and mole fraction \& mass faction value was found to be $0.89 \%$ and $0.69 \%$. Table 7 summarizes the Absolute Deviation and Absolute Percentage Error for Higher Heating Value between experimental value and mole fraction \& mass faction method value.

Based on the study, it was clearly evident that the thermo physical properties like density, Kinematic Viscosity, Cetane Number, Higher Heating Value are based on the properties of individual fatty acid esters. Equation 5 demonstrates the significant contribution of Ethyl Palmitate, Ethyl Oleate, Ethyl Stearate, and Ethyl Myristate in these thermophysical properties owing to their higher concentration than compared to other characterized fatty acid esters.

However, these equations are limited with certain restrictions in predicting thermo physical properties which are as follows:

(i) Equations for predicting density and Kinematic Viscosity are restricted for temperatures $15^{\circ} \mathrm{C}$ and $40^{\circ} \mathrm{C}$ respectively, owing to development of mathematical equation based on the data series obtained at these temperatures. Equations incorporating temperature as the third variable along with the existing variables can be developed to find these properties at different temperatures.

(ii) These equations are applicable only for fatty acid esters of ethyl group and fails for other alkyl esters. However, these equations still stands applicable for all other fatty acid ethyl esters.

\section{Stoichiometric air to fuel ratio:}

Stoichiometric air to fuel ratio defines the requirement of air for complete combustion of $1 \mathrm{~mol}$ of fuel and the combustion products are resultant of oxidation on Carbon, hydrogen and oxygen molecules in the fuel, the equation for complete combustion can be written as shown in Equation 9 [14].

$$
\mathrm{C}_{\mathrm{N}_{\mathrm{C}}}+\mathrm{H}_{\mathrm{N}_{\mathrm{H}}}+\mathrm{O}_{\mathrm{N}_{\mathrm{O}}}+\mathrm{N}_{\text {Air }}\left(\mathrm{O}_{2}+3.776 \mathrm{~N}_{2}\right) \rightarrow \mathrm{pCO}_{2}+\mathrm{qH}_{2} \mathrm{O}+\left(3.776 * \mathrm{~N}_{\text {Air }}\right) \mathrm{N}_{2}
$$

On balancing equation 9, the balance of carbon, hydrogen, oxygen and nitrogen can be used to calculate the stoichiometric amount of air (in terms of moles) required for complete combustion by substituting in Equation 10. [14].

$$
N_{A I R}=\frac{4 N_{C}+N_{H}+4 N_{O}}{8}
$$

The molecular formula of biodiesel from rendered waste beef tallow was formulated using the number of carbon, hydrogen and oxygen molecule calculated using the GC spectra data and was found to be $\mathrm{C}_{18} \mathrm{H}_{35} \mathrm{O}_{2}$. On substituting the number of carbon, hydrogen and oxygen molecules as 18,35 and 2 respectively in Equation 10, the amount of air (in moles) required for combusting one mole of biodiesel was calculated as 25.75. Based on calculated Nair, the Stoichiometric air to fuel ratio was found to be 12.54:1. However, 1.5 times the calculated amount of stoichiometric air must be supplied to the engine for biodiesel to undergo complete combustion thereby making the actual stoichiometric ratio as 18.9:1[14].

\section{CONCLUSIONS:}

Thus, the thermos-physical properties of beef tallow based biodiesel were predicted and evaluated successfully by employing simple empirical correlations. The beef tallow biodiesel was characterized and 
quantified for fatty acid esters using Gas Chromatography spectra and; standard thermos-physical properties of quantified fatty acid esters were summarized from standard tables and existing literatures. Empirical correlations were developed from these standard values for properties like density, kinematic viscosity, Cetane number, higher heating value using simple molecular properties like molecular weight and number of double bonds. The accuracy of developed correlations were ensured by comparing the experimental and calculated value of properties of individual fatty acid esters and also mass fraction \& mole fraction were used to compare the experimental value and calculated value of properties of Beef tallow biodiesel. Average Absolute deviation and Average absolute percentage error were determined for all the values to ensure minimum deviation between the experimental and calculated values and was found to be permissible thereby enabling these correlations for theoretical study and prediction purposes.

\section{REFERENCES:}

1. Srinivasan, G.R. and Jambulingam, R., 2018. Comprehensive Study on Biodiesel Produced from Waste Animal Fats-A Review. Journal of Environmental Science and Technology, 11, pp.157-166.

2. Srinivasan, G.R., Srinivasan, S.R., Venkatachalapathy, D. and Venkatachalapathy, N., 2017. Production, performance, combustion, emission characteristics of biodiesel synthesized from mutton suet. Int. J. Eng. Technol, 9, pp.3512-3518.

3. Knothe, G., 2005. Dependence of biodiesel fuel properties on the structure of fatty acid alkyl esters. Fuel processing technology, 86(10), pp.1059-1070.

4. Gopinath, A., Puhan, S. and Nagarajan, G., 2009. Theoretical modeling of iodine value and saponification value of biodiesel fuels from their fatty acid composition. Renewable Energy, 34(7), pp.1806-1811.

5. Gouw, T.H. and Vlugter, J.C., 1964. Physical properties of fatty acid methyl esters. I. Density and molar volume. Journal of the American Oil Chemists' Society, 41(2), pp.142-145.

6. Allen, C.A., Watts, K.C., Ackman, R.G. and Pegg, M.J., 1999. Predicting the viscosity of biodiesel fuels from their fatty acid ester composition. Fuel, 78(11), pp.1319-1326.

7. Krisnangkura, K., Yimsuwan, T. and Pairintra, R., 2006. An empirical approach in predicting biodiesel viscosity at various temperatures. Fuel, 85(1), pp.107-113.

8. Allen, C.A., Watts, K.C. and Ackman, R.G., 1999. Predicting the surface tension of biodiesel fuels from their fatty acid composition. Journal of the American Oil Chemists' Society, 76(3), pp.317-323.

9. Ejim, C.E., Fleck, B.A. and Amirfazli, A., 2007. Analytical study for atomization of biodiesels and their blends in a typical injector: surface tension and viscosity effects. Fuel, 86(10-11), pp.1534-1544.

10. Klopfenstein, W.E., 1985. Effect of molecular weights of fatty acid esters on Cetane Numbers as diesel fuels. Journal of the American Oil Chemists' Society, 62(6), pp.1029-1031.

11. Srinivasan, G.R., Palani, S. and Jambulingam, R., 2018. Biodiesel Production from Waste Animal Fat using a Novel Catalyst HCA Immobilized AuNPS Amine Grafted SBA-15. Journal of Engineering Science and Technology, 13(8), pp.2632-2643.

12. Srinivasan, G.R., Palani, S. and Jambulingam, R., 2018. Optimised Production of Biodiesel Synthesised from Waste Animal Fat. Journal of Biofuels, 9(1), pp.17-24.

13. Barabás, I. and Todoruț, I.A., 2011. Biodiesel quality, standards and properties. In Biodiesel-quality, emissions and by-products. InTech.

14. Srinivasan, G.R. and Jambulingam, R., Experimental Study on influence of dominant Fatty Acid Esters in Engine Characteristics of Waste Beef Tallow Biodiesel. Energy Exploration \& Exploitation. (Artice in Press). 